\title{
Study of the Xi'an Xiao Yan pagoda's dynamic characteristics
}

\author{
Tao Yang ${ }^{1 \mathrm{a}}$, Nan Zhao ${ }^{1 \mathrm{~b}}$, She-liang Wang ${ }^{1 \mathrm{c}_{*}}$
}

${ }^{1}$ School of Civil Engineering, Xi'an University of Architecture and Technology, No. 13 Yanta Road, Xi'an, Shaanxi Province, P.R. China

ayangtao0604@163.com, bxingyue_liuyun@163.com, cwangshel@aliyun.com

Keywords: dynamic characteristics; reinforcement; earthquake; seismic performance

\begin{abstract}
Finite element software ABAQUS was used to calculate the dynamic characteristics of Xi'an Xiao Yan pagoda by a three-dimensional entity model, and a variety of factors were simulated on its dynamic characteristics. Results show that it is feasible to calculate the structural dynamic characteristics by a finite element three-dimensional entity model. Through model comparison process, it was found that tilted wall is favorable to the seismic performance. And the elastic-plastic time-history analysis was carried out to simulate the tower under the big earthquake damage, and the corresponding reinforcement measures were discussed according to the simulation results.
\end{abstract}

\section{Introduction}

Xi'an Xiao Yan pagoda located in Jianfu temple, is a dense canopy tower in the Tang dynasty. and it had 15 original layers formerly, and now it exists 13 layers with 43.4 meters in height[1][2]. The Xi'an Xiao Yan pagoda has experienced many times of earthquake and received damages in history. As a precious historical and cultural heritage, its seismic performance research is particularly important. It is shown in figure 1.

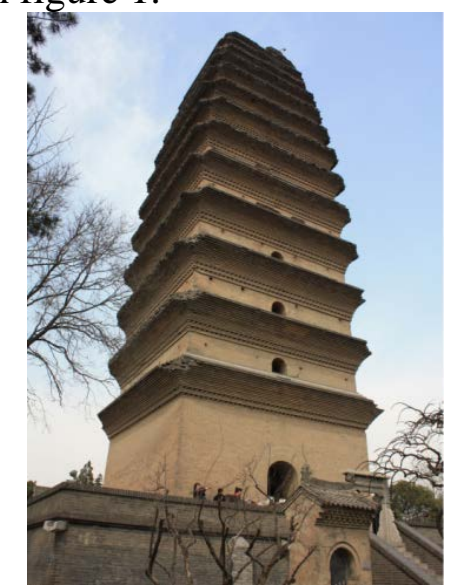

Fig.1 Xi’an Xiao Yan pagoda

In the recent years, the domestic scholars have a lot of researches in the view of old tower's seismic performance, such as Chen Ping' discussion on the Xi'an Xiao Yan pagoda. Chen put forward that the weakness of the perforated brick pagodas was that the axis of shear capacity in tower body was low, so the seismic reinforcement should be paid attention to[3][4].Yuan Jianli concluded the modeling methods, and analyzed the main factors that influenced the model. At last, he put forward the classic theory and the modeling methods which combines test data and the computer simulation[5][6].

However, the research of the influence of tower structure on the dynamic characteristics is still insufficient. This paper calculates the dynamic characteristics of the Xi'an Xiao Yan pagoda's three-dimensional entity finite element model by the finite element software ABAQUS, studies the feasibility of ABAQUS' simulation on the dynamic characteristics of masonry pagodas structures, simulates the door opening, the form of wall, and the roof overhang three factors' influence on its dynamic characteristics, summarizes the influence of several factors on the simulation results. Then the finite element model of tower was put into elastic-plastic time-history analysis, which attempted to simulate the tower's collapse state under earthquakes. Finally, several methods of reinforcement 
were presented according to the results of finite element simulation, which was seen as some references for the reinforcement of Xi'an Xiao Yan pagoda.

\section{Basic parameters}

Due to the several earthquakes, Xi'an Xiao Yan pagoda suffered severe damages, and it didn't have initial bricks in the subsequent reparation, so the strength of the blocks were large discreted, which was verified through our site springback experiment. The value of Young's modulus was based on the literature[1], and it was reduce to $E=1500 \mathrm{Mpa}$, Poisson ratio was $\mu=0.15$, density was $\rho=1900 \mathrm{~kg} / \mathrm{m} 3$. Tower body geometry sizes (table 1 ) were measured at actual field.

Table 1 Xi'an Xiao Yan pagoda real geometry size (unit: $\mathrm{m}$ )

\begin{tabular}{cccccc}
\hline level & length & Floor height & Wall thickness & Hole height & Outer hole Width \\
\hline 13 & 6.50 & 1.45 & 1.82 & 0.37 & 0.37 \\
12 & 7.15 & 1.54 & 1.94 & 0.37 & 0.40 \\
11 & 7.72 & 1.60 & 2.20 & 0.40 & 0.49 \\
10 & 8.00 & 1.98 & 2.26 & 0.60 & 0.54 \\
9 & 8.56 & 2.28 & 2.50 & 0.80 & 0.59 \\
8 & 9.13 & 2.47 & 2.78 & 0.80 & 0.62 \\
7 & 9.44 & 2.62 & 2.85 & 0.85 & 0.66 \\
6 & 9.87 & 2.82 & 3.00 & 1.20 & 0.74 \\
5 & 10.10 & 3.18 & 3.10 & 1.22 & 0.76 \\
4 & 10.30 & 3.34 & 3.20 & 1.36 & 0.88 \\
3 & 10.50 & 3.45 & 3.28 & 1.40 & 0.94 \\
2 & 10.86 & 3.75 & 3.38 & 1.45 & 0.97 \\
1 & 11.40 & 6.84 & 3.57 & 2.68 & 1.77 \\
\hline
\end{tabular}

\section{The establishment of the finite element model}

This paper adopted finite element analysis software ABAQUS, and employed the method of three-dimensional entity modeling (as shown in figure 2) and element type $\mathrm{C} 3 \mathrm{D} 10 \mathrm{H}$, and the automatic mesh generation method was employed, and it produced 72158 units (as shown in figure 3). The Xi'an Xiao Yan pagoda's former six ranks natural vibration period and frequency is shown in table 2, which indicated the model has good agreement with experimental data. Figure 4 is the former six figure vibration modes. The first two ranks translated along the north-south, east-west respectively, because its symmetrical structure, natural frequency difference was little, and the third rank vibration mode was a reverse along the vertical direction. The ratio of the first cycle, which took torsion as its main movement, and the first cycle, which took translation as its main movement, shows that the bearing layout is reasonable, and the structure will be better controlled under severe sensation of torsion effect. The sixth rank vibration mode was structural vibration along the vertical, and the top part of the tower had the biggest vertical deformation. Moreover, the top part was at the most unfavorable position except torsional vibration, and structural section size decreases along the height direction from the bottom to the top. The minimum cross section is at the top of the tower, and the shear and tensile strength are all minimum here, so there should be paid attention to the reinforcement.

Table 2 Natural vibration period and frequency of the vibration model

\begin{tabular}{cccccc}
\hline Number & $\begin{array}{c}\text { Natural } \\
\text { frequency of } \\
\text { vibration (Hz) }\end{array}$ & $\begin{array}{c}\text { Natural } \\
\text { vibration } \\
\text { period (s) }\end{array}$ & Number & $\begin{array}{c}\text { Natural } \\
\text { frequency of } \\
\text { vibration (Hz) }\end{array}$ & $\begin{array}{c}\text { Natural } \\
\text { vibration } \\
\text { period (s) }\end{array}$ \\
\hline 1 & 1.3182 & 0.759 & 4 & 5.0598 & 0.198 \\
2 & 1.3557 & 0.738 & 5 & 5.1637 & 0.194 \\
3 & 4.1432 & 0.241 & 6 & 6.4060 & 0.156 \\
\hline
\end{tabular}




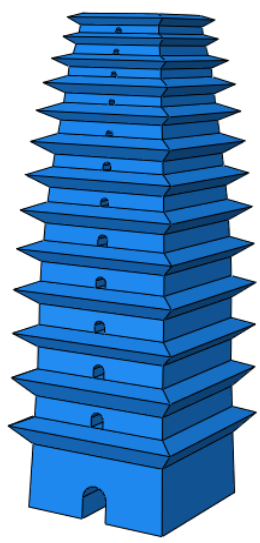

Fig.2 basic mode

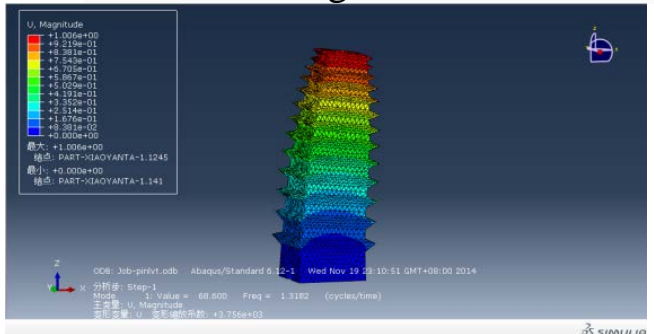

(a) Vibration mode of the first rank

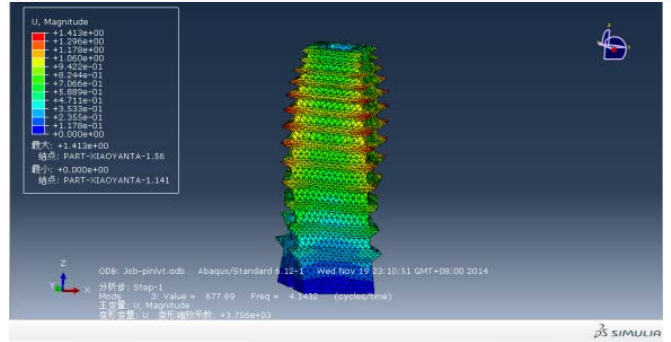

(c) Vibration mode of the third rank

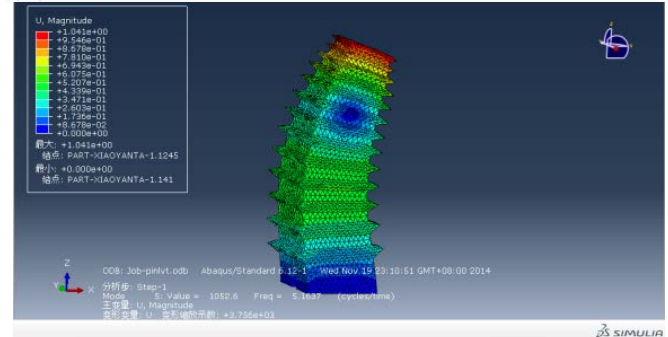

(e) Vibration mode of the fifth rank

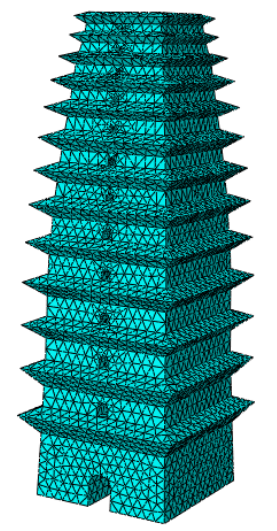

Fig.3 after the meshing model diagram

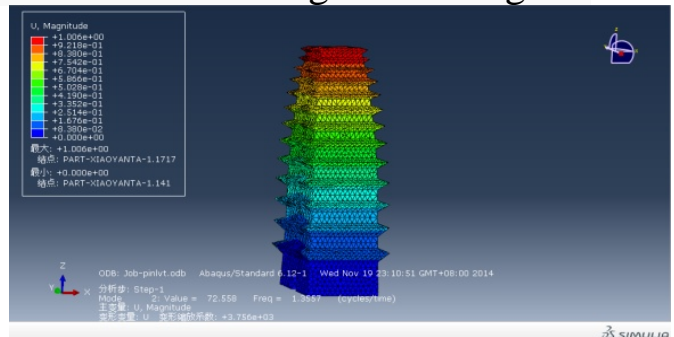

(b) Vibration mode of the second rank

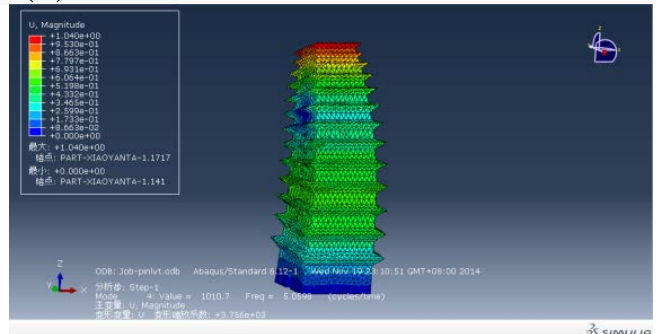

(d) Vibration mode of the forth rank

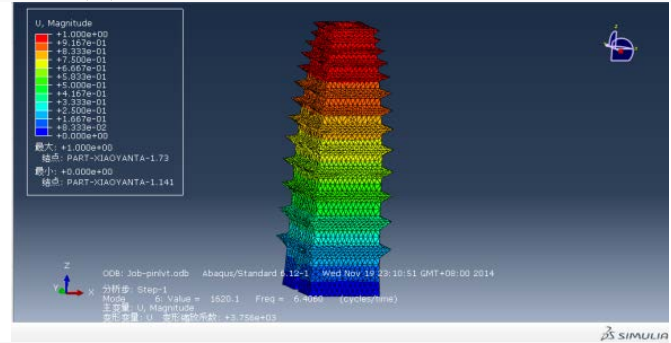

(f) Vibration mode of the sixth rank

Fig.4 Basic modes of vibration

\section{The effect of door opening}

Door opening of the Xi'an Xiao Yan pagoda were set on the walls in the north and south in each layer, and the hole shape are almost the same, while its size reduce step by step upwards. The situation of no-door opening, which was studied in this paper, was compared with the original model of the structure, and the result was shown in figure 5. The result of numerical modeling indicated that windows and door hole have little affect on the dynamic characteristics of the structure, less than $5 \%$, which is negligible. In fact, the hole's influence on the tower body is very big, and there was a history record that the Xi' an Xiao Yan pagoda cracked from the top to the foot under a strong earthquake with a magnitude of 6.25.

The structure which cracked along the vertical axis was mainly caused by shearing strength. Tower made of bricks -which can be regarded as a fixed cantilever bar- can produce maximum, shearing strength in the neutral axis of bending bar under earthquakes, and the Xi'an Xiao Yan pagoda was opened several holes in the north and south on the neutral axis, which can increase the 
possibility of the earthquake damages. In this paper, the holes' simulation results which has little impact is due to consideration of computer memory limit, and the entity unit was adopted when modeling were different from structural actual situation. In fact, blocks of the Xi'an Xiao Yan pagoda are brittle material, and there is different degrees of weathering about the yellow slurry used in the structure. Therefore, it still need some attention in the process of structure strengthening.

Table 3 simulation of the natural vibration period with none hole

\begin{tabular}{ccccc}
\hline number & $\begin{array}{c}\text { Natural } \\
\text { frequency of } \\
\text { vibration }(\mathrm{Hz})\end{array}$ & $\begin{array}{c}\text { Natural } \\
\text { vibration } \\
\text { period }(\mathrm{s})\end{array}$ & $\begin{array}{c}\text { Prime natural } \\
\text { vibration period } \\
(\mathrm{s})\end{array}$ & $\begin{array}{c}\text { Relative } \\
\text { differences } \\
(\%)\end{array}$ \\
\hline 1 & 1.3640 & 0.733 & 0.759 & 3.43 \\
2 & 1.3640 & 0.733 & 0.738 & 0.68 \\
3 & 4.3236 & 0.231 & 0.241 & 4.15 \\
4 & 5.2380 & 0.191 & 0.198 & 3.54 \\
5 & 5.2381 & 0.191 & 0.194 & 1.55 \\
6 & 6.5470 & 0.153 & 0.156 & 1.92 \\
\hline
\end{tabular}

\section{The influence of inclined wall}

The spectacular beautiful exterior of the Xi'an Xiao Yan pagoda benefits from that all the walls' natural adduction along the height direction, and each wall was laied out symmetrical and its size did not change suddenly, making its stability increased, and it is conducive to the overall structural anti-seismic performance. The success of the Xi'an Xiao Yan pagoda's anti-seismic performance shows that the building size can reduce the torsion effect, and can make the interlayer resistance in harmony with the seismic force, avoiding to a weak part in lower part. In this sense, the Xi'an Xiao Yan pagoda is a unique charm that can stand there for one thousand years. Simplified finite element model is presented in this paper. In the model, wall was assumed vertical, and the wall thickness was according to the actual size, and the modal analysis results were listed in table 4 . Table 4 shows that the structure of the Xi'an Xiao Yan pagoda's natural adduction has a bigger natural frequency and a greater stiffness than traditional vertical wall structure under the same overall dimensions, which is also beneficial to structural anti-seismic performance.

Table 4 Simulation of natural vibration period with vertical wall mode

\begin{tabular}{ccccc}
\hline number & $\begin{array}{c}\text { Natural } \\
\text { frequency of } \\
\text { vibration }(\mathrm{Hz})\end{array}$ & $\begin{array}{c}\text { Natural } \\
\text { vibration } \\
\text { period }(\mathrm{s})\end{array}$ & $\begin{array}{c}\text { Prime natural } \\
\text { vibration } \\
\text { period }(\mathrm{s})\end{array}$ & $\begin{array}{c}\text { Relative } \\
\text { differences } \\
(\%)\end{array}$ \\
\hline 1 & 1.1891 & 0.841 & 0.759 & -10.80 \\
2 & 1.2225 & 0.818 & 0.738 & -10.84 \\
3 & 3.6890 & 0.271 & 0.241 & -12.45 \\
4 & 4.9102 & 0.204 & 0.198 & -3.03 \\
5 & 5.0212 & 0.199 & 0.194 & -2.58 \\
6 & 5.9272 & 0.169 & 0.156 & -8.33 \\
\hline
\end{tabular}

\section{Conclusions}

Through the analysis above, we get the following conclusions:

(1) When establishing a dynamic analysis model, vertical wall has a big influence on its dynamic characteristics, and the form of natural adduction is conducive to the anti-earthquake performence.

(2) In this paper, the finite element model was established to simulate the Xi'an Xiao Yan pagoda's anti-earthquake performence in 8 degrees, showing that Xi'an Xiao Yan pagoda may has less capacity for anti-earthquake under strong earthquake seismic, and the position of the tower body reinforcement can be determined through the simulation results.

(3) Reinforcement of the tower can adopt bar between mesh, slip casting at brickwork joint, carbon fiber reinforcement, and new material damper to achieve a better reinforcement effect, and the combination of the above methods can also be considered. 


\section{References}

[1] Chen Ping, Zhao Dong Yao Qianfeng. An exploration of the aseismic behavior of Xi'an Xiao Yan Pagoda [J]. Journal of Xi' an University of Architecture \& Technology.,1999,31(2),149 152

[2] Zhao Xiang, Wang She-liang, Zhou Fu-lin, et al. Shaking table tests for ancient pagoda model structure based on shape memory alloy actuating devices ,J. Journal of Vibration Shock. 30(2011):219-223.

[3] Zhang Wenming. Studies on aseismic behavior evaluation and seismic broken mechanics of ancient masonry pagodas[D]. Xi' an: Xi' an University of Architecture \& Technology,2008

[4] Liu Xiao-feng,Cai Xian-hui, Cheng Gengdong. Earthquake damage of masonry buildings and anchorage-tie strengthening method for rural houses [J]. Journal of Dalian University of Technology,2009,49(5),631 638

[5] Wang Feng-hua, Zhou FuIin, Huang Xiang-yun. Application and optimization analysis of new type shape memory alloy damper in seismic strengthening of ancient tower [J]. Earthquake Resistant Engineering and Retrofitting,2011,33(2),43 49

[6] Wang Sheliang, Su Sanqing, Shen Yapeng. Seismic response analysis for passive structural control with shape memory alloy tendons [J] China Civil Engineering Journal,2000,33(1),56 62 